\title{
Effect of oxytocin on haemodynamic change during caesarean section under spinal anaesthesia - A comparison between intravenous bolus or infusion technique
}

\author{
Golam Murshid"1, Idris Ali², Amirul Islam ${ }^{3}$, Sabina yeasmeen ${ }^{3}$, Nurul Islam ${ }^{4}$, Nitai \\ Chandra Sarkar ${ }^{5}$, Azizul Gafur ${ }^{6}$, Abdul $\mathrm{Hye}^{7}$ \\ ${ }^{1}$ Sadar Hospital, Chuadanga, ${ }^{2}$ Dhaka Dental College Hospital, Dhaka. ${ }^{3,7}$ Department of Anaesthesia, Analgesia \& \\ Intensive Care Medicine, BSMMU, Shahbag, Dhaka. ${ }^{4}$ Department of Anaesthesiology and ICU, DMCH, Dhaka, \\ ${ }^{5}$ Chuadanga Health Complex, Kushtia, ${ }^{6}$ Department of Anaesthesiology, Jahurul Islam Medical College \& Hospital, \\ Bajitpur, Kishorganj \\ *Correspondence: E-mail: dramirul68@yahoo.com
}

\begin{abstract}
Background Subarachnoid block for caesarean section is very acceptable technique and it rates are steadily increasing in recent years. It is now spreading up to remote areas. Infusion technique of oxytocin is safe during caesarean section under spinal anaesthesia.
\end{abstract}

Objective To compare the haemodynamic changes caused by oxytocin given as an I/V bolus or infusion to decrease uterine bleeding in caesarean section.

Method A total number of sixty patients ASA grade I were selected. Thirty patient in each group. In group $A$, parturient received oxytocin $5 I U$ of $I / V$ in bolus and group B, infusion of oxytocin $5 I U$ diluted with $5 \mathrm{ml}$ normal saline given I/V over 2 min by using infusion pump. The study period was started just before oxytocin given and it was continued for a further $10 \mathrm{~min}$. Systolic and diastolic BP, MAP, heart rate, uterine bleeding were recorded in every $1 \mathrm{~min}$.

Result The mean difference of all haemodynamic parameters at 2 to 5 mins of administration of oxytocin were statistically significant $(p<0.05)$.

Conclusion The haemodynamic changes were more marked in $I / V$ bolus of oxytocin than infusion technique.

Key words: Oxytocin, bolus, infusion, haemodynamic, intravenous.

(JBSA 2011; 24(2): 48-52)

\section{Introduction}

Caesarean section is a very common surgical procedure for delivery of baby and it rates are steadily increasing in recent years and regional anesthesia has become the preferred technique ${ }^{1}$. Maternal hypotension is a recognized complication of subarachnoid block which may compromise the welfare of both mother and fetus and some times it may lead to a dangerous complication, cardiac arrest leading to remarkable number of mortality and morbidity ${ }^{3}$.

Oxitocin, ergot derivatives and prostaglandins are extensively used in clinical practice ${ }^{4}$. The doses schedule of oxytocin drugs in induction and augmentation should aim to initiate effective contraction leading to decreased blood loss, good uterine contraction and good obstetric outcome ${ }^{5}$.After caesarean section uterus relaxes. We use some technique to contract uterus. Manual stimulation sometimes causes uterus contraction. Usually we use some drugs e.g. ergometrine and oxytocin etc. to contract uterus. Ergometrine causes nausea, vomiting, vesoconstriction as a result increased blood pressure and $\mathrm{CVP}^{6}$.

Oxytocin is an octapeptide hormone secreted mainly from posterior pituitary gland, is a potent 
stimulant that is essential after caesarean section ${ }^{7}$. Oxytocin causes uterine contraction as well as decrease bleeding after caesarean section but it cause hypotension and tachycardia 8 .

In this study, we tried to find out the effect (haemodynamic change at heart rate, blood pressure and uterine contraction) of the recommended dose (ie 5IU) of Oxytocin when given as IV bolus or slow IV infusion diluted in $5 \mathrm{ml}$ of distilled water over 2 minutes during caesarean section under spinal anesthesia.

\section{Methods}

A total number of sixty patients undergoing elective caesarean section ASA grade-I were selected randomly as per inclusion and exclusion criteria in two groups. In group A, parturient received 5IU oxytocin IV bolus and group B received slow infusion of oxytocin diluted with $5 \mathrm{ml}$ normal saline over 2 minutes by using infusion pump.

Each parturient pre medicated with cap. omeprazole $20 \mathrm{mg}$ orally. 1 cap. at evening before and 1 cap. at morning of operation. Arterial blood pressure and heart rate, $\mathrm{Spo}_{2}$ were recorded. A $18 \mathrm{G}$ IV cannula will be inserted and ringer's lactate solution preloaded $10 \mathrm{ml}$ per $\mathrm{kg}$ body weight and IV drip was given same as body weight during caesarean section.

With all aseptic precaution spinal anesthesia was given at L3/4 space in sitting position and $2.0 \mathrm{ml}$. $0.5 \%$ Bupivacaine heavy was given intrathecally. Then patient was kept in supine position with left sided with wedge in right buttock and oxygen was given intraoperatively with nasal cannula. After testing the height and quality of the block urinary catheterization was done and surgeon allowed starting the operation. After delivery of the fetus group A received 5IU oxytocin (inj. Piton-S) bolus (Approximately over $1 \mathrm{sec}$ ) and group $\mathrm{B}$ received 5IU oxytocin (inj. Piton-S) IV infusion slowly diluted with $5 \mathrm{ml}$ normal saline over $2 \mathrm{~min}$. Baseline data was taken before oxytocin given.

Patient was monitored every 3min interval up to the delivery of the fetus. After delivery of the fetus patient was monitored systolic and diastolic BP, MAP, heart rate, oxygen saturation, uterine contraction, uterine bleeding and any adverse effect was recorded in every $1 \mathrm{~min}$ in data sheet.
The study period was started just before oxytocin given and it was continued for a further $10 \mathrm{~min}$. The study period of 10 min was set after a small pilot study. Patient was observed by surgeon the state of uterine contraction expressed as mild, moderate or fully contracted. Uterine bleeding was calculated after suctioning amniotic fluid and blood in separate bottle and visually estimating the blood by surgical sponger and laparotomy pads (laps). A fully soaked sponge $(4 \times 4)$ each side to hold $10 \mathrm{ml}$ of blood, where as a soaked MOP holds 100-150ml. Quantitative definition of postpartum hemorrhage was arbitrary and related to the amount of blood loss in excess of $500 \mathrm{ml}$ following birth of the baby.

At the end of surgery 200 microgram misoprostal per-rectally was given of each patient. Postoperatively patient was monitored the state of uterine contraction, $\mathrm{P} / \mathrm{v}$ bleeding and cardiovascular status.

All the relevant information for each of the study was recorded on predigined data sheet with the help of volunteers as per requirements.

The result complied and analyzed statistically by unpaired-t test with a $\mathrm{p}$ value $<0.05$ with $95 \%$ confident limit.

\section{Results}

Observation of the present study was analyzed in the light of comparison among the subject groups, each group having $\mathrm{n}=30$.All results are expressed as mean \pm standard deviation. The studied groups became statistically matched for age, gestational age, weight heart rate, systolic and diastolic blood pressure, mean arterial pressure.

Table I : Demographic data

\begin{tabular}{lccc}
\hline Group & $\begin{array}{c}\text { Age(yrs) } \\
\text { Mean } \pm \text { SD }\end{array}$ & $\begin{array}{c}\text { Gestational } \\
\text { age(weeks) } \\
\text { Mean } \pm \text { SD }\end{array}$ & $\begin{array}{c}\text { Weitht(Kg) } \\
\text { Mean } \pm \text { SD }\end{array}$ \\
\hline A & $24.1 \pm 6.0$ & $39.4 \pm 0.7$ & $59.3 \pm 3.0$ \\
B & $25.1 \pm 4.7$ & $39.6 \pm 0.8$ & $59.9 \pm 2.3$ \\
P & 0.489 & 0.360 & 0.327 \\
\hline
\end{tabular}

Values were expressed as mean \pm SD. Analysis was done by unpaired t-test. There was no significant difference between the groups. 
Table II Changes of heart rate

\begin{tabular}{cccccccccccc}
\hline & $\begin{array}{c}\text { Pre } \\
\text { operative }\end{array}$ & $\begin{array}{c}1 \\
\min \end{array}$ & $\begin{array}{c}2 \\
\min \end{array}$ & $\begin{array}{c}3 \\
\min \end{array}$ & $\begin{array}{c}4 \\
\min \end{array}$ & $\begin{array}{c}5 \\
\min \end{array}$ & $\begin{array}{c}6 \\
\min \end{array}$ & $\begin{array}{c}7 \\
\min \end{array}$ & $\begin{array}{c}8 \\
\min \end{array}$ & $\begin{array}{c}10 \\
\min \end{array}$ \\
\hline $\mathrm{A}$ & $85.7 \pm 3.9$ & $92.3 \pm 10$ & $98 \pm 2.8$ & $101 \pm 5.1$ & $102 \pm 7.5$ & $105 \pm 5.2$ & $93.2 \pm 2.3$ & $92.5 \pm 3.0$ & $94.4 \pm 12$ & $95.4 \pm 10$ & $94 \pm 11$ \\
$\mathrm{~B}$ & $87.7 \pm 5.2$ & $91.3 \pm 11$ & $92.6 \pm 2.2$ & $90 \pm 4.4$ & $87 \pm 6.6$ & $90 \pm 2.1$ & $90.4 \pm 3.5$ & $89.3 \pm 2.6$ & $93.7 \pm 8.2$ & $95.5 \pm 12$ & $95 \pm 11$ \\
$\mathrm{p}$ & 0.10 & 0.72 & 0.00 & 0.02 & 0.01 & 0.02 & 0.46 & 0.38 & 0.82 & 0.95 & 0.95 \\
\hline
\end{tabular}

Values were expressed as mean \pm SD. Analysis was done by unpaired t-test. The above table shows the heart rate of preoperative and just after giving oxytocin up to 10 minutes one minute interval. There were significant difference between the groups from $2 \mathrm{~min}$ to $5 \mathrm{~min}$. $(\mathrm{p}<0.05)$.

Table III : Changes of systolic blood pressure

\begin{tabular}{cccccccccccc}
\hline & $\begin{array}{c}\text { Pre } \\
\text { operative }\end{array}$ & $\begin{array}{c}1 \\
\min \end{array}$ & $\begin{array}{c}2 \\
\min \end{array}$ & $\begin{array}{c}3 \\
\min \end{array}$ & $\begin{array}{c}4 \\
\min \end{array}$ & $\begin{array}{c}5 \\
\min \end{array}$ & $\begin{array}{c}6 \\
\min \end{array}$ & $\begin{array}{c}7 \\
\min \end{array}$ & $\begin{array}{c}8 \\
\min \end{array}$ & $\begin{array}{c}9 \\
\min \end{array}$ & $\begin{array}{c}10 \\
\min \end{array}$ \\
\hline A & $117 \pm 7.8$ & $116 \pm 7.5$ & $100 \pm 7.3$ & $95.5 \pm 5.4$ & $96.5 \pm 4.5$ & $97.3 \pm 4.5$ & $100 \pm 8.1$ & $104 \pm 11$ & $104 \pm 10$ & $105 \pm 10$ & $103 \pm 11$ \\
$\mathrm{~B}$ & $120 \pm 6.9$ & $119 \pm 6.7$ & $108 \pm 6.9$ & $108 \pm 4.3$ & $107 \pm 3.6$ & $106 \pm 3.6$ & $105 \pm 7.4$ & $108 \pm 11$ & $108 \pm 12$ & $107 \pm 11$ & $107 \pm 10$ \\
$\mathrm{p}$ & 0.16 & 0.10 & 0.02 & 0.00 & 0.02 & 0.03 & 0.16 & 0.12 & 0.24 & 0.40 & 0.40 \\
\hline
\end{tabular}

Values were expressed as mean \pm SD. Analysis was done by unpaired t-test. The above table shows the systolic blood pressure of preoperative and just after giving oxytocin up to 10 minutes one minute interval. There were significant difference between the groups from $2 \mathrm{~min}$ to $5 \min .(\mathrm{p}<0.05)$.

Table IV : Changes of diastolic blood pressure

\begin{tabular}{cccccccccccc}
\hline & $\begin{array}{c}\text { Pre } \\
\text { operative }\end{array}$ & $\begin{array}{c}1 \\
\min \end{array}$ & $\begin{array}{c}2 \\
\min \end{array}$ & $\begin{array}{c}3 \\
\min \end{array}$ & $\begin{array}{c}4 \\
\min \end{array}$ & $\begin{array}{c}5 \\
\min \end{array}$ & $\begin{array}{c}6 \\
\min \end{array}$ & $\begin{array}{c}7 \\
\min \end{array}$ & $\begin{array}{c}8 \\
\min \end{array}$ & $\begin{array}{c}9 \\
\min \end{array}$ & $\begin{array}{c}10 \\
\min \end{array}$ \\
\hline $\mathrm{A}$ & $76.3 \pm 5.6$ & $72.8 \pm 8.5$ & $50.5 \pm 3.8$ & $60 \pm 9.9$ & $60.8 \pm 3.6$ & $61.3 \pm 3.6$ & $70.1 \pm 4.3$ & $65.3 \pm 9.1$ & $68.3 \pm 8.1$ & $67 \pm 8.7$ & $67.7 \pm 8.5$ \\
$\mathrm{~B}$ & $78.7 \pm 4.3$ & $73.5 \pm 8.9$ & $55.0 \pm 3.6$ & $73.7 \pm 8.1$ & $73.3 \pm 4.9$ & $72.6 \pm 4.8$ & $74.9 \pm 4.9$ & $67.5 \pm 8.4$ & $69.7 \pm 7.9$ & $69 \pm 9.6$ & $69.7 \pm \mathrm{S} 10$ \\
$\mathrm{P}$ & 0.07 & 0.71 & 0.03 & 0.02 & 0.01 & 0.03 & 0.31 & 0.42 & 0.52 & 0.88 & 0.88 \\
\hline
\end{tabular}

Values were expressed as mean \pm SD. Analysis was done by unpaired t-test. The above table shows the Diastolic blood pressure of preoperative and just after giving oxytocin up to 10 minutes one minute interval. There were significant difference between the groups from $2 \mathrm{~min}$ to $5 \min .(\mathrm{p}<0.05)$.

Table V : Changes of mean arterial pressure

\begin{tabular}{cccccccccccc}
\hline & Pre & 1 & 2 & 3 & 4 & 5 & 6 & 7 & 8 & 9 & 10 \\
& operative & $\min$ & $\min$ & $\min$ & $\min$ & $\min$ & $\min$ & $\min$ & $\min$ & $\min$ & $\min$ \\
\hline A & $90 \pm 6$ & $86.4 \pm 5.8$ & $64.3 \pm 5.4$ & $64.2 \pm 6.2$ & $65.3 \pm 5.8$ & $64.7 \pm 4.2$ & $69.9 \pm 5.3$ & $67.9 \pm 5.3$ & $68.5 \pm 8.3$ & $69 \pm 6.9$ & $64.6 \pm 6$ \\
B & $92.4 \pm 3.9$ & $86.3 \pm 6.2$ & $72 \pm 6$ & $74.7 \pm 7.3$ & $73.4 \pm 6.2$ & $74.3 \pm 5.3$ & $74.8 \pm 6.4$ & $70.8 \pm 6.4$ & $71.6 \pm 9.1$ & $72.1 \pm 7.7$ & $72.1 \pm 4.7$ \\
$\mathrm{p}$ & 0.06 & 0.94 & 0.00 & 0.03 & 0.03 & 0.01 & 0.35 & 0.25 & 0.36 & 0.24 & 0.16 \\
\hline
\end{tabular}

Values were expressed as mean \pm SD. Analysis was done by unpaired t-test. The above table shows the mean arterial pressure of preoperative and just after giving oxytocin upto 10 minutes observed one minute interval. There were significant difference between the groups from $2 \mathrm{~min}$ to $5 \mathrm{~min}$ $\mathrm{p}<0.05$. 
Table VI : Distribution of PPH in both groups

\begin{tabular}{lccccc}
\hline Complications & \multicolumn{2}{c}{ Group A } & & \multicolumn{2}{c}{ Group B } \\
\cline { 2 - 3 } \cline { 5 - 6 } & $\mathrm{n}$ & $\%$ & & $\%$ \\
\hline Ignored bleeding $<$ & 30 & 100 & & 30 & 100 \\
$500 \mathrm{ml}$ & & & & \\
$\begin{array}{l}\text { Postpartum } \\
\text { haemorrhage }\end{array}$ & 0 & 0.0 & & 0 & 0.0 \\
\hline
\end{tabular}

The above table shows the PPH of patients and found all patients ignored bleeding $<500 \mathrm{ml}$ in both groups.

\section{Discussion}

This prospective, interventional study was carried with an objective to compare the haemodynamic changes caused by oxytocin given as an I/V bolus or infusion to decrease uterine bleeding in caesarean section under spinal anaesthesia. A total of 60 pregnant women age between 18 to 36 years weight between $55 \mathrm{~kg}$ to $65 \mathrm{~kg}$ belonging physical status ASA grade I with term pregnancy ( 37 weeks and above) undergo elective caesarean section under spinal anaesthesia were enrolled in this study. These patients were divided into two groups of thirty patients each formed by randomly selected patients by blind envelope method. Out of which 30 were included in group A received 5IU oxytocin bolus (approximately over $1 \mathrm{sec}$ ) and 30 in group $\mathrm{B}$, received 5IU oxytocin IV infusion diluted with $5 \mathrm{ml}$ normal saline over 2 minutes.

This study shows that slower infusion of 5IU oxytocin can effectively minimize the cardiovascular side-effects but rapid bolus oxytocin causes marked cardiovascular instability without compromising the therapeutic benefits.

The current study demonstrated an average decrease in MAP of $24 \mathrm{mmHg}$ range from 19 to 32 $\mathrm{mmHg}$ in group A during 2 to 5 minutes in healthy women having an elective caesarean section who received 5IU of oxytocin as a rapid bolus. Whereas in group B average decrease in MAP of $12 \mathrm{mmHg}$ range from 8 to $18 \mathrm{mmHg}$ during 2 to 5 minutes. Whilst this magnitude of decrease in MAP may be well tolerated normally.

In the present study it was observed that the changes in heart rate were significantly higher in group A with compared to group B during 2 to 5 minutes. However, the gentler increase of heart rate in the infusion group (group B) is preferable clinically. It is reassuring to the anaesthetiologist who prefers to maintain cardiovascular status that this physiological insult can be avoided simply by giving 5IU oxytocin infusion over $2 \mathrm{~min}$. Thomas JS (2006) and his colleague found in their study that the decrease in MAP of 8(8.7) $\mathrm{mmHg}$ and the small increase in HR are certainly clinically preferable, which is closely resemble with the present study. ${ }^{29}$

Obviously there have been discussions within the obstetric anaesthesia community about the correct dose of oxytocin and its method of administration. ${ }^{30}$ Despite the controversy it seems more anesthetiologist are using the lower dose of 5IU as recommended by the $\mathrm{CEMD}^{31}$. This is supported by the work of Pinder and colleagues ${ }^{9}$ who showed dose-related haemodynamic effects, although they underestimated the potential reduction in MAP attributable to the usage of lower dosage by showing greater haemodynamic stability when $5 \mathrm{IU}$ is administered over $5 \mathrm{~min}$.

Whilst the cardiovascular results of this study are unequivocal, it was acceptable that $<500 \mathrm{ml}$ bleeding during caesarean section was ignored in this study. Uterine contraction and urine output were in satisfactory level in both groups. Post partum haemorrhage was observed in the present study between two groups.

This study reports the need for caution using oxytocin as a bolus in cardiovascular unstable patients and offers relative reassurance of the effect when given as an infusion over 2 minutes. concluded that the haemodynamic changes were more marked in IV bolus group than IV slow infusion group. Slower injection of oxytocin can effectively minimize the cardiovascular side-effects as well as equally effective in reducing blood loss without compromising the therapeutic benefits.

\section{References}

1. Critehly LAH, Stuart JC, Conway, short TG. Volume Preloading, Spinal anesthesia, Lower uterine Caesarean section, BJA 1995; 373-78

2. S Bhagwanjee, DA Rocker, CC Rout, R.V. Koovarjee and R. Bridal, Prevention of hypotension following spinal anaesthesia for elective caesarea section by wrapping of the legs. BJA 1990; 65: 819-22 
3. Auroy Yves, Narchi, Patrick, messiah, kamran, et al. Serious complication related to regional anaesthesia result in a prospective survey in France anesthesiology 1997;87: 479-86

4. Dutt DC, Pharmacotherapeutics in obstetrics, Text book of obstetric and gerontology and contraception, $6^{\text {th }}$ edition Calcutta; New central book agency (P) Ltd. 2004;33:498

5. Ratnam SS. Bashket K RAO, Arulkumaran S. induction of labour, obstetric and gynaecology, orient Longman Ltd. 1994; 16(2): 198

6. RE.Garfield PHD, and S. Beir, PHD. Increased myometrial responsiveness to oxytocin during term and preterm labor. Am J Ot Gyn 1989; 161: 54-61

7. Zeeman Gh, Khan, Dawood MY. oxytocin and its receptor in pregnency and parturition; Current concepts and clinical implication, obstet Gynaecol 1997; 89(5):873-88

8. Daniel-Spiegel E, Weiner Z, Ben- Sholmo 1, Shalev E. For how long should oxytocin be continued during induction of labour? $\mathrm{Br} \mathrm{J}$ obstet Gynaecol 2004; 111:331-34

9. Pinder AJ, Dresner M, Calow C, O'Riordan J, Johnson R, Haemodynamic changes caused by oxytocin during caesarean section under spinal anaesthesia, Int J Obstet anesth 2002;11:156-9

10. Weis FR Jr, Markello R, Mo B, Bochiecsio P. Cardiovascular effects of oxytocin, obstet Gynecol 1975; 46:211-14

11. Dawood MY. Novel approach to oxytocin induction- augmentation of labour application of oxytocin physiology during pregany Adv Exp Medbiol 1995;555-94

12. Hendricks $\mathrm{CH}$ and Brenner WE. Cardiovascular effects of oxytocin drugs used post partum, American Journal of obstet Gynecol 1970; 108:751-60

13. Gutko washa J, Jankowski M, Mukaddam Daher S, Mc Cann SM. Oxytocin is a cardiovascular hormone, Braz J of Mad Biol Res 2000;33:625-33

14. Thomas J.S, Koh S.H and Cooper G.M Haemodynamic effects of oxyticin given as i.v. bolus or infusion on women undergoing caesarean section BJA. 2007; 98(1): 116-119

15. Capeless EL, Clapp-J. Cardiovascular change in erely phase of pregnancy. Am J obstet Gynecol. 1989; 161:1449-53
16. Robson SC. Hunter S. Boys R Dunlop W, Serial factors influencing changes in cardiac output during human pregnancy. Am J Physiol 1989;23:1060-65

17. Clark S, Cotton DB, Lee W, et al. Central haemodynamic assessment of normal term pregnancy. Am J obstet Gynecol 1989; 161: 1439-42

18. Kinsella SM, Lohmann G. Supine Hypotension syndrome. obstet Gynecol 1994;83:774-87

19. Kerr MG, Scott DB, Samuel E, Studies of the inferior vena cava in late pregnancy BMJ. 1994;1:532-3

20. Bieniarz J, Yoshida T, Romario - Salins G. at al. Aortocaval compression by the uterus in late human pregnancy, IV Cirulatory haemostasis by preferential prefusion of the placenta. Am J obstet Gynecol 1969;103:19-31

21. Kinsella SM, Wihitwam JG, Spencer JAD. Aortic compression by the uterus, identification with the Finapress digital arterial pressure instrument. Br J obstet Gynecol. 1990;700-5

22. Parer Jt, Shinder SM. Uteroplacental circulation and respiratory gass exchange. Anaesthesia for obstetrics, $2^{\text {nd }}$ End. 1987;14-21

23. Stuarf JC, Kan AF, Robatom SY, Young, OGTE, Acid aspiration prophylaxis for emergency caesarean section, Anaesthesia 1996;51:415-21

24. Clinical Anaesthesiology G. Edward Morgan Jr, Maged S. Mikhail, $2^{\text {nd }}$ edn 1992;p.220

25. Russel IF, Holmqvist ELO. Subarachnoid analgesia for caesarean section, A double blind comparison of plain and hyperbaric $0.5 \%$ bupivacaine, BJA 1987; 59:347-53

26. Morgan B, Unexpectedly extensive conduction block in obstetric epidural analgesia, Anaesthesia 1990;45:148-52

27. Endelman JD, Wingard DW, Subdural haematomas after lumber Puncture. Anaesthesiology

28. Reid JA, Thorburm J, Headache after spinal Anaesthesia, BJA 1991;67:674-76

29. Rosaeg OP, Licutti NJ, Labow RS. The effects of oxytocin on the contractile force of human atrial trabeculae. Anesth Analg 1998;86:40-4

30. Scrutton M. Update in obstetric Anaesthesia oxytocin: What does and why? Anaesthesia Points West.2004;37:28-30 